\title{
The Effects of Strategy and Mathematics Anxiety on Mathematical Creativity of School Students
}

\author{
Yogesh Sharma \\ Ramgarhia College Of Education, Phagwara, Punjab, India
}

\begin{abstract}
The purpose of the present investigation was to study the effects of strategy, mathematics anxiety and their interaction on mathematical creativity of school students. A total of 111 class IX students participated in the study. Out of which, 59 were taught with the strategy for fostering mathematical creativity developed during the study, and 52 were considered for the control group and continued with the routine mathematics classroom activities. The strategy for fostering mathematical creativity was found to be effective for developing mathematical creativity. However, mathematics anxiety was a crucial factor, as strategy for fostering mathematical creativity was found to be better suited to students with low mathematics anxiety than students with high mathematics anxiety when groups were matched with respect to pre-mathematical creativity. The study calls for the need to provide increased opportunities for students to increase competency in mathematical creativity.
\end{abstract}

Keywords: Strategy for Fostering Mathematical Creativity, Mathematical Creativity, Mathematics Anxiety

\section{INTRODUCTION}

Creative thinking is rapidly becoming a common purpose throughout the world (Strom \& Strom, 2002) and cultivating better creative thinking ability in students has become an important trend in educational revolution (Hwang, Chen, Dung \& Yang, 2007). However, this need becomes fundamental in case of mathematics as Kapur (1990) argued that one of the purest forms of creative effort is in mathematics as it does not greatly depend on availability of equipment, or on complexity of social phenomenon, while Silver (1997) held that mathematics as an intellectual domain stands at or near the top of any hierarchical list of intellectual domains ordered according to the extent to which creativity is evident in disciplinary activity or production. Moreover, an increasing number of educators, researchers, and agencies of education assert that there need to foster mathematical creativity among students (NCTM, 2000; Singh, 2004; Mann, 2006; Shiriki, 2010; Fetterly, 2010; Bolden, Harries and Newton, 2010). Further, according to Sriraman (2004), mathematical creativity ensures the growth of the field of mathematics as a whole. And, a survey conducted in USA shows that $91 \%$ of the students agreed that creativity is part of mathematics and acknowledged the importance of creativity in learning mathematics (Brunkalla 2009). Furthermore, Fetterly (2010) pointed out that the NCTM's vision is the kind of creative mathematics that will produce the changes necessary to meet the demands of the unknown problems our children will face, while Shiriki (2010) held that the teachers 
must be able to design and implement learning environments that support the development of mathematical creativity.

In order to develop mathematical creativity, the classroom activities and curricular materials are needed to be reorganized. Previously efforts have been made by the researchers, like, Miyan, 1982; Meyer, 1969; Singh, 1985; Moghe, 1996; Shriki, 2010; and Fetterly, 2010. However, there is need to develop more strategies, as Singh (2004) mentioned that only one strategy is not sufficient to deal with either all the branches of mathematics or various topics related to them. The more strategies are also needed to deal with different types of students (gifted/average/backward) and psycho-social environments of the mathematics classrooms.

Further, it has been found that mathematics anxiety is negatively and significantly related with mathematics performance and achievement (Liebert \& Morris, 1967; Richardson \& Suinn, 1972; Morris, Davis \& Hutchings, 1981; Sarason, 1986; Eccles \& Jacobs, 1986; Wigfield \& Meece, 1988; Cooper \& Robinson, 1989; Hembree, 1990; Engelhard, 1990; Green, 1990; Tocci \& Engelhard, 1991; Ma, 1999; Ma \& Xu, 2004; Zakaria \& Nordin, 2007; Olantunde, 2009). But, not much is known about the relationship between mathematics anxiety and mathematical creativity. Only, Haylock (1987b), Johny (2008) and Fetterly (2010) studied the relationship between mathematics anxiety and mathematical creativity. Haylock (1987b) and Johny (2008) found that mathematical creativity was significantly and inversely related to mathematics anxiety. However, Fetterly (2010) neither confirmed nor denied the significant relationship between mathematical creativity and mathematics anxiety.

Thus, keeping in mind that mathematical creativity is topical and little is known about the effect of mathematics anxiety on fostering of mathematical creativity, it was thought to study the effect of strategy, mathematics anxiety and their interaction on mathematical creativity of school students. The specific research questions addressed in the study were:

1. Is the developed strategy effective in fostering mathematical creativity?

2. Is there a difference between students who have high mathematics anxiety versus low mathematics anxiety in regard to their mathematical creativity scores?

3. Is there an interaction between treatment and mathematics anxiety in regard to mathematical creativity?

\section{Theoretical Background}

Creative thinking has strong links across various disciplines (NCF, 2005; Neumann, 2007). Cheng (2011) synthesized the views of some profound western scholars and argued that a full model of creativity education should include various cognitive and skill-based trainings, as well as the development of student interest, value and confidence in creativity pursuits. However, mathematics educators have acknowledged that problem-posing and problem-solving, along with overcoming fixation are the aspects necessary for the development of mathematical creativity (Hadamard, 1945; Aiken, 1973; Balka, 1974b; Krutetski, 1976; Haylock, 1987, 1987a, 1997; NCTM, 1989; Ernest, 1991; Silver, 1994, 1997; Silver, Mamona-Downs, Leung and Kenny, 1996; Becker and Shimada, 1997; Sriraman, 2005; Bolden, Harries and Newton, 2009). For example, NCTM (1989) recommended that students should have some experience recognizing and formulating their own problems, an activity that is at heart of doing mathematics. Hadamard (1945) identified the ability to find key research questions as an indicator of exceptional talent in the domain of mathematics. Silver, Mamona-Downs, Leung and Kenny (1996) mentioned that problem posing is of central importance in the discipline of mathematics and in the nature of mathematical thinking, while Ernest (1991) identifies mathematics as social institution, resulting from human problem posing and solving. Mathematical creativity is the ability to open avenues of new questions for other mathematicians (Sriraman, 2005). The teacher fostering creativity is the one who poses problems, asks question, encourages discussion, and provides opportunity to observe and explore "in the mathematical 
laboratory" (Aiken 1973). It is appropriate for elementary teachers to consider divergent open-ended items in their classes to identify and encourage mathematical creativity (Balka 1974). The framework adopted by Haylock (1987a, 1987b, 1997) for recognition and development of mathematical creativity includes, overcoming fixation and divergent production tasks in mathematics. Researchers at Japan's National Institute for Educational Research conducted a six-year research study that evaluated higher-order mathematical thinking using open-ended problems (problems with multiple correct answers). In a roundtable review of the study, Sugiyama from Tokyo Gakugei University affirmed this approach as a means to allow students to experience the first stages of mathematical creativity (Becker \& Shimada, 1997). Bolden, Harries and Newton (2009) summarizes that the creative opportunities in mathematics classroom are in, for example, the need for mathematical expression and communication, the construction of meaning and development of personal understandings, the generation of ways of solving problems, hypothesizing about mathematical situations and outcomes, constructing tests of those hypotheses and in formulating plans for solving complex problems.

Thus, mathematical creativity was operationally defined as an ability to overcome fixation as well as conceptualizing, proposing, and even testing unusual solutions of problem(s) of mathematics. Moreover, the review of the literature indicates that cooperative interaction has considerable impact on the stimulation of creativity (John-Steiner, 2000; Sriraman, 2005; Neumann, 2007; NCTM, 2000; Shriki, 2010). Keeping this in view, the strategy was designed on the premise that mathematical creativity can be fostered with the help problem posing and problem solving activities in a cooperative learning environment with proper feedback. This intervention is called strategy for fostering mathematical creativity and it has three phases.

Phase I (Warm Up): The task of the first phase was to sensitize the students about the unlimited number of responses that a mathematical problem can have. In this phase, a mathematical problem demanding divergent answers was posed by the teacher. The problem was then solved by the teacher with the active participation of the students. Students were encouraged and prompted to think different solutions of the problem. Efforts were made to get at least one response from each student. The responses were simultaneously written on the board.

Phase II (Cooperative Confrontation): The second phase of the strategy for fostering mathematical creativity aimed to bring into play the synergy for finding various solutions to a mathematics problem posed by the teacher, a collaborative manner on a worksheet. The students were grouped and each group consisted of 4-5 students. During the process the teacher motivated the groups, presenting a competition amongst groups to identify which group brought forth maximum number of original answers. After 5 minutes, the worksheets were taken back. For the responses feedback was provided by the teacher. For this, original as well as inappropriate responses of the groups were written on the board. The feedback helped the students to know about the appropriateness of the response. As Haylock (1997) mentioned, a mathematical response may be highly original but it is of little use if it is not appropriate within accepted mathematical criteria. However, students were neither encouraged nor discouraged to make inappropriate response as discouragement to make inappropriate yet original response may have negative effect(s) on students' imagination.

Phase III (Independent Thought): In Phase three each student tried to pose a problem similar to the one they solved in the second phase. The problems posed by all the students were collected. The problems were checked by the investigator and correct problems were written on the board. In order to expedite the process, 2-3 students were requested to write problems on the board. Each student was required to solve at least one problem on the worksheet. They had the freedom to choose a problem out of the various problems written on the board. The problems were solved without the help from the teacher or the peer(s). This aimed at bringing independent mastery of the activity. At the end, the worksheets were collected. The feedback about the relevance of the responses was provided on next working 
day. The role of the teacher was supportive and motivating. The sample lessons based on strategy for fostering mathematical creativity are given in the Appendix B.

\section{METHOD}

\section{Participants}

The sample for the field stage comprised of 111 grade IX students ranging from $14-17$ years belonging to three different schools. The sample was selected through cluster random sampling technique. Out of 111,59 students (31 males and 28 females) were in the experimental group and 52 (32 males and 20 females) in control group. Furthermore, 82 students were from urban area and 29 were from rural area. The medium of instruction was English.

\section{Measure}

Sharma and Sansanwal Mathematical Creativity Test ( $\left.S^{2} M C T\right)$. In the present study $S^{2} M C T$ developed by Sharma and Sansanwal (2012) was used as a measure of mathematical creativity. The $\mathrm{S}^{2} \mathrm{MCT}$ had a total of 20 items pertaining to problem solving, problem posing, and overcoming fixation in mathematical situations. The items of S2MCT were individually time limited. The items were scored for fluency $(\mathrm{F})$, flexibility $(\mathrm{X})$, and originality (O). The test-retest reliability of the S2MCT was .86 and the Cronbach's alpha was .78. A sample of items of $S^{2} M C T$ has been given in the Appendix A.

Mathematics Anxiety Scale (MAS). The MAS developed by Sharma and Sansanwal (2011) was used as a measure of mathematics anxiety. The MAS comprises 44 items pertaining to cognitive and affective dimensions. There was no time limit but generally students took 25 minutes. Moreover, there were 22 positive statements and 22 negative statements. The weight age given for positive statements was 1, 2 and 3 for yes, undecided and no, while, in case of negative statements the weight age given was 3,2 and 1 for yes, undecided and no. The test-retest reliability and split-half reliability coefficients were reported as .80 and .82 respectively. They also reported a criterion validity (The mathematics achievement test developed by L.N. Dubey was used as a measure of mathematics achievement) as -.74.

Reaction towards Strategy for Fostering Mathematical Creativity Scale. The reaction towards strategy for fostering mathematical creativity was assessed with the help of Reaction towards Strategy for Fostering Mathematical Creativity Scale constructed by the investigator. There were 24 statements related to different aspects of strategy for fostering mathematical creativity, such as, cooperative learning, level of difficulty, interest, and classroom environment. Against each statement a five-point scale was given. The five points were Strongly Agree (SA), Agree (A), Undecided (UN), Disagree (D) and Strongly Disagree (SD). The students were asked to read each statement carefully and put a tick mark on any one alternative that represents their reaction towards that aspect of the strategy for fostering mathematical creativity. There were 12 positive and 12 reverse statements. There was no time limit for responding this reaction scale. However, students generally took $15-$ 20 minutes. The items of Reaction towards Strategy for Fostering Mathematical Creativity Scale can be seen in the Table 2 .

\section{Procedure}

The present study was experimental in nature. The study was designed on the lines of the non-equivalent control group design (Campbell and Stanley, 1963). There were two groups. One group was designated as experimental group and the other as control group. However, the schools were randomly assigned to the treatment.

Both the groups were pre-tested by administering $\mathrm{S}^{2} \mathrm{MCT}$. In order to overcome the problems of administration, the items of $\mathrm{S}^{2} \mathrm{MCT}$ were divided into three parts - $\mathrm{A}, \mathrm{B}$ and $\mathrm{C}$. 
The time required for Part A, Part B and Part C was 35 minutes, 35 minutes and 34 minutes respectively. It did not include the time required to give instructions. Moreover, as the items of S2MCT were individually time limited, the participants were instructed by the researcher to move to the next item. The students were encouraged to write as many different and original responses as they can. However, they were not told about the criteria $(\mathrm{F}, \mathrm{X}, \mathrm{O})$ used to score their responses on $\mathrm{S}^{2} \mathrm{MCT}$. The pre-testing of mathematical creativity with $\mathrm{S} 2 \mathrm{MCT}$ was completed in three consecutive days.

The students of experimental group were taught through the lessons based on strategy for fostering mathematical creativity developed by the investigator. Each day one period was taken. The duration of one period was 35 minutes. This continued for 40 days. On the other hand, no treatment was provided to control group. The control group continued with the routine mathematics activities and traditional method was used to teach mathematics. In traditional method, convergent mathematics problems are solved by the teacher on the board and students are required to solve similar problems independently, without any assistance. Furthermore, the students of the control group were not given any information about the strategy for fostering mathematical creativity.

At the end of the treatment, both the groups were again post - tested with $\mathrm{S}^{2} \mathrm{MCT}$. The scheme of post-testing was similar to that of pre -testing. Moreover, on fifth day of the treatment, MAS was administered on participants of both experimental and control groups. This was done to assess mathematics anxiety of students.

\section{RESULTS}

A $2 \times 3$ (treatment $\times$ mathematics anxiety) analysis of covariance (ANCOVA), with premathematical creativity as the covariate, was performed on the students' mathematical creativity score on S2MCT. The ANCOVA indicated significant effect for treatment level, $F$ $(1,104)=44.06, \mathrm{p}<0.01$; and interaction $\mathrm{F}(2,104)=4.02, \mathrm{p}<0.05$. No significant main effect for mathematics anxiety was found. The adjusted and unadjusted mean scores for these factors are presented in Table 1. An examination of the means indicated that students belonging to strategy for fostering mathematical creativity group had significantly $(p<0.01)$ greater adjusted mean score than students of traditional method of teaching mathematics.

Table 1. Adjusted (and unadjusted) mathematical creativity means on MCT

\begin{tabular}{|c|c|c|c|}
\hline \multirow{2}{*}{ Treatment Level } & \multirow{2}{*}{ Mathematics Anxiety Level } & \multicolumn{2}{|c|}{ Grade IX } \\
\hline & & $\mathbf{N}$ & $\mathbf{M}$ \\
\hline Strategy for & High & 7 & $425.77(273.43)$ \\
\hline mathematical creativity & Intermediate & 39 & $517.59(575.28)$ \\
\hline & Low & 13 & $671.37(917.85)$ \\
\hline Total & & 59 & $538.24(614.95)$ \\
\hline Routine mathematics activities & High & 10 & $305.10(118.20)$ \\
\hline and traditional method of & Intermediate & 39 & $254.56(166.21)$ \\
\hline teaching & Low & 13 & $229.80(273.89)$ \\
\hline Total & & 52 & $263.15(175.62)$ \\
\hline
\end{tabular}

In order to know the trend of effect of interaction between treatment and mathematics anxiety on mathematical creativity of students by considering pre-mathematical creativity as covariate, Graph 1 has been plotted. 


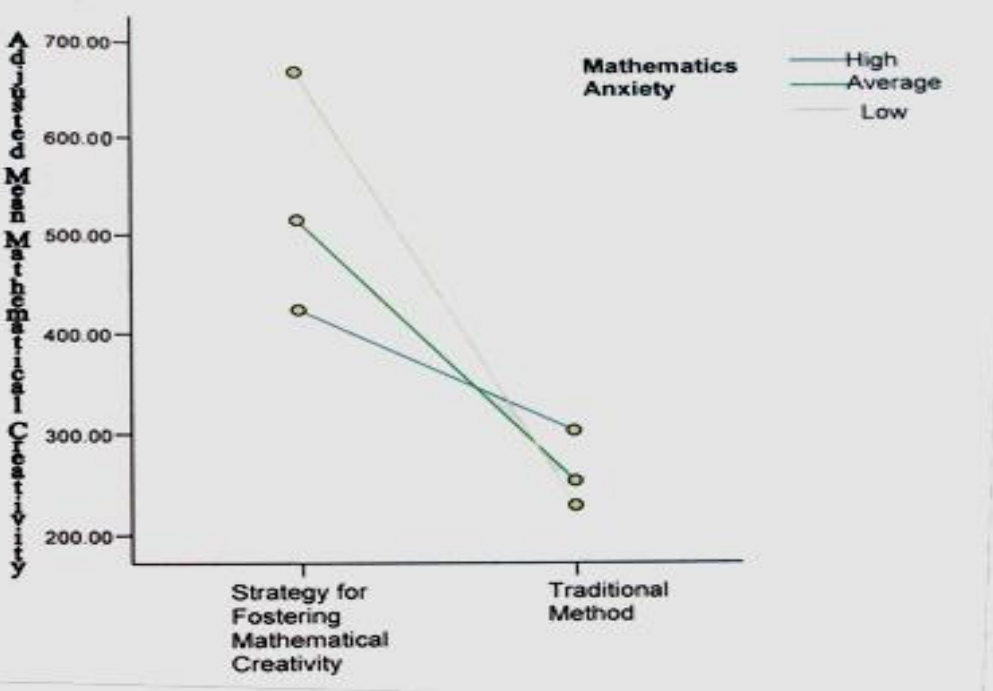

Graph 1. Trend of effect of interaction between treatment and mathematics anxiety on mathematical creativity by considering pre-mathematical creativity as covariate

From Graph 1, it can be seen that in strategy for fostering mathematical creativity group, students with high mathematics anxiety had significantly lower adjusted mean score of mathematical creativity as compared to the students with average and low mathematics anxiety. On the other hand, in traditional method group, students with high mathematics anxiety had significantly higher adjusted mean score of mathematical creativity as compared to the students with average and lower mathematics anxiety. Also, it can be seen from the Graph 1 that in strategy for fostering mathematical creativity group, students with average mathematics anxiety had significantly lower adjusted mean score of mathematical creativity as compared to the students with low mathematics anxiety, while, in traditional method group, students with average mathematics anxiety had significantly higher adjusted mean score of mathematical creativity as compared to the students with low mathematics anxiety. In the light of these observations, it can be concluded that students with low mathematics anxiety can be benefited significantly more through strategy for fostering mathematical creativity in comparison to students with high and average mathematics anxiety when pre-mathematical creativity was considered as covariate.

\section{DISCUSSION}

Strategy for fostering mathematical creativity was found to enhance mathematical creativity significantly and it was superior to traditional method in fostering mathematical creativity when groups were matched with respect to pre-mathematical creativity. The finding is supported by Miyan (1982), Singh (1985), Moghe (1996) and Fetterly (2010). That is to say that still more strategies can be developed for enhancing mathematical creativity. Strategy for fostering mathematical creativity was found to facilitate mathematical creativity of students significantly more than traditional method of teaching mathematics. This might be because students exposed to strategy for fostering mathematical creativity were given different exercises where they were made to think divergently. Students exposed to strategy may have been more active during the process of treatment. The students possibly got opportunity to share their responses. It may have helped in widening their cognitive domain. Each student's responses were checked and feedback was given. It might have helped them to know the status of their mathematical creativity in relation to other peers. It might have motivated them to think differently. The assumptions made here were premised on the information collected from the students of experimental group on reaction towards strategy fostering mathematical creativity scale (see Table 2). 
Table 2. Statement wise percentage of responses belonging to different categories

\begin{tabular}{|c|c|c|c|c|c|c|}
\hline Sr. & Item & SA & $\mathbf{A}$ & $\mathbf{U}$ & $\mathbf{D}$ & SD \\
\hline 1 & Working in a group was wastage of time. & 15 & 5 & 0 & 22 & 58 \\
\hline 2 & Problems were difficult to understand. & 5 & 22 & 19 & 32 & 22 \\
\hline 3 & Problems were according to level of the students. & 54 & 29 & 9 & 5 & 3 \\
\hline 4 & Classroom environment was boring. & 3 & 5 & 17 & 31 & 44 \\
\hline 5 & Problems were challenging. & 46 & 29 & 15 & 8 & 2 \\
\hline 6 & Problems solved in the class were below the level of the students. & 7 & 13 & 32 & 19 & 29 \\
\hline 7 & Problems solved in the class were above the level of the students. & 9 & 15 & 15 & 29 & 32 \\
\hline 8 & Working in a group did not help in generating different solutions of the given & 8 & 7 & 12 & 27 & 46 \\
\hline 9 & Working in a group did help to find different solutions of the same problem. & 54 & 27 & 2 & 12 & 5 \\
\hline 10 & Problems stimulated thinking. & 41 & 27 & 27 & 3 & 2 \\
\hline 11 & Generating different solutions of the same problem was not interesting. & 7 & 13 & 17 & 29 & 34 \\
\hline 12 & Formulating problems was exciting. & 41 & 30 & 15 & 12 & 2 \\
\hline 13 & Students knew before hand the solutions of problems solved in the class. & 22 & 22 & 25 & 12 & 19 \\
\hline 14 & Students were free to speak their answers. & 59 & 26 & 3 & 9 & 3 \\
\hline 15 & Problems solved in the class were interesting. & 58 & 31 & 8 & 3 & 0 \\
\hline 16 & There should be more classes like that. & 42 & 44 & 9 & 0 & 5 \\
\hline 17 & Teacher's help was not required. & 15 & 8 & 22 & 31 & 24 \\
\hline 18 & Such type of problems should also be given by teachers of science. & 27 & 36 & 19 & 10 & 8 \\
\hline 19 & Students hesitated to share their ideas with peers. & 5 & 10 & 19 & 34 & 32 \\
\hline 20 & More ideas can be generated in small group of FOUR students. & 44 & 34 & 5 & 14 & 3 \\
\hline 21 & Whenever required teacher's help was available. & 58 & 27 & 12 & 3 & 0 \\
\hline 22 & The classroom setting was not motivating. & 7 & 12 & 32 & 27 & 22 \\
\hline 23 & All students generated solutions of the given problem. & 49 & 31 & 10 & 10 & 0 \\
\hline 24 & On the whole the exercises were boring. & 10 & 3 & 7 & 22 & 58 \\
\hline
\end{tabular}

On the other hand, in case of traditional method, teacher was active but students may have been passive listener. They possibly did not get opportunity to think divergently. They could have solved numerical problems where solutions were fixed and no scope of thinking divergently. In case students failed to solve problem, the teacher might have solved it on the board without teaching them the process of arriving at the solution. These might be the 
reasons of superiority of strategy for fostering mathematical creativity in comparison to traditional method of teaching mathematics.

Mathematics anxiety was not found to be a significant correlate of mathematical creativity when groups were matched with respect to pre-mathematical creativity. This finding is contradicted by Haylock (1987) and Johny (2008). But, it is in line with the results reported by Fetterly (2010). Mathematics anxiety refers to learned phenomenon on account of which an individual has negative cognito-affective reactions (worryfear/tension/physiological reactions) towards mathematics. This can happen in case of performance in traditional school mathematics. Mathematical creativity is different from what taught in schools in the name of mathematics. In mathematical creativity students do not give responses which are designated as correct or incorrect. Mathematical creativity and invention are aspects of 'doing' mathematics that have long been accepted as standing outside of the theories of "logical forms" (Dewey 1938). Many students (and adults) who fear mathematics are in fact quite capable of thinking mathematically, and do so quite oftenparticularly in their attempts to avoid mathematics! What they really fear is not mathematics itself, but school mathematics (Cockcroft 1982). While, answering to the items of MCT, students may have enjoyed doing mathematics. They possibly have found problems given in MCT interesting and different from the routine school mathematics problems. So, the students may have worked solutions of problem without any worry, tension, fear, or being nervous. Thus, mathematics anxiety might not have been found to be a significant correlate of mathematical creativity.

Strategy for fostering mathematical creativity was found to be better suited to students with low mathematics anxiety than students with high mathematics anxiety when groups were matched with respect to pre-mathematical creativity. The reason of this finding might be because students having low mathematics anxiety were relaxed, tension free and calm in comparison to those who had high mathematics anxiety. In this study the treatment had two levels, namely, strategy for fostering mathematical creativity and traditional method. Students of strategy for fostering mathematical creativity were given exercises where they were to think of different solution of the given problem. Students of traditional method were not given any especially designed problems but they solved problems given in the textbook having one answer and required convergent thinking rather than divergent thinking. In strategy for fostering mathematical creativity students were required to think of different solutions of each given problem. Generating different solutions of the given problem required open and tension free mind. This was available with students having low mathematics anxiety. On the other hand, in the traditional method, students with high mathematics anxiety may have perceived mathematical creativity problems as recreational activities. The researcher while conducting S2MCT observed that the students in traditional group were excited and interested to deal with mathematical creativity as, it was different from their routine mathematics. So, they may not have felt the negative effects of mathematics anxiety while dealing with the problems of mathematical creativity. Thus, students with low mathematics anxiety were found to benefit significantly more from strategy for fostering mathematical creativity than their counter parts with high mathematics anxiety. Though, the researcher feels that the limitation of the study is that no qualitative data was taken from the students of control group to ascertain the exact cause of the present finding.

In sum, the study has implications for students, teachers, teacher educators, administrators, parents, and society. And, opportunities must be given to the students and teachers to enhance their mathematical creativity by working with strategy for fostering mathematical creativity.

\section{Acknowledgements}

The author is thankful to Dr. Pranita Gopal for initial review of the manuscript. 


\section{REFERENCES}

Aiken, L.R. (1973). Ability and creativity in mathematics. Review of Educational Research, 43(4), 405-432.

Balka, D.S. (1974). Creative ability in mathematics. The Arithmetic Teacher, 21(7), 633-636.

Becker, J.P., \& Shimada, S. (1997). The openended approach: A new proposal for teaching mathematics. Reston, VA: National Council of Teachers of Mathematics.

Bolden, D.S., Harries, T.V., \& Newton, D.P. (2009). Pre-service primary teachers' conception of creativity in mathematics. Educational Studies in mathematics, 73(2), 143-157. doi: 10.1007/s 10649-009-9207-z

Brunkalla, K. (2009). How to increase mathematical creativity - An experiment. The Montana Mathematics Enthusiast, 6(1\& 2), 257-266.

Campbell, D.T., \& Stanley, J.C. (1963). Experimental and Quasi-Experimental designs for Research in teaching. In N.L. Gage (Ed.), Handbook of research on teaching - A project of the American Educational Research Association. Chicago: Rand McNally and Company.

Cheng, V. M. Y. (2011). Infusing creativity into Estern classrooms: Evaluations from student perspectives. Thinking Skills and Creativity, 6(1), 67-87. doi:10.1016/j.tsc.2010.05.001

Cockroft, S.W. (1982). Mathematics counts. London: Her Majesty's Stationary office.

Cooper, S.E., \& Robinson, D.A.G. (1989). The Influence of gender and anxiety on mathematics performance. Journal of College Student Development, 30(5), 459461.

Dewey, J. (1938). Logic: The theory of inquiry. NY: Henry Holt and Company.

Eccles, J.S., \& Jacobs, J.E. (1986). Social forces shape math attitudes and performance. Signs: Journal of Women in Culture and Society, 11(2), 367-380.

Engelhard, G., Jr. (1990). Math anxiety, mother's education, and the mathematics

performance of adolescent boys and girls: Evidence from United States and Thailand. Journal of Psychology, 124, 289-298.

Ernest, P. (1991). The philosophy of mathematics education. London: The Falmer Press.

Fetterly, J.M. (2010). An exploratory study of the use of a problem-posing approach on pre- service elementary education teachers' mathematical creativity, beliefs, and mathematics anxiety (doctoral dissertation, College of Education, The Florida State University). Retrieved from http://diginole.lib.fsu.edu

Hadamard, J. W. (1945). Essay on the psychology of invention in the mathematical field. Princeton, NJ: Princeton University Press.

Hwang, W.Y., Chen, N.S., Dung, J.J., \& Yang, Y.L. (2007). Multiple representation skills and creativity effects on mathematical problem solving using a multimedia whiteboard system. Educational Technology \& Society, 10 (2), 191-212. Retrieved from http://www.ifets.info/journals/10_2/17.pdf

Haylock, D.W. (1987a). A framework for assessing mathematical creativity in school children. Educational Studies in Mathematics, 18, 59-74.

Haylock, D.W. (1987b). Mathematical creativity in school children. The Journal of Creative Behavior, 21(1), 48-59.

Haylock, D.W. (1997). Recognizing mathematical creativity in school children. International Reviews on Mathematical Education, 29(3), 68-74. Retrieved from http://www.emis.de/journals/ZDM/zdm97 3a2.pdf

Hembree, R. (1990). The nature, effects, and relief of mathematics anxiety. Journal of Research in Mathematics Education, 21(1), 33-46.

Johny, S. (2008). Effect of some environmental factors on mathematical creativity of secondary school students of Kerla (India). Proceedings of the $11^{\text {th }}$ Congress on Mathematical Education, Monterrey, Mexico. Retrieved from dg.icme11.org/document/get/293

John-Steiner, V. (2000). Creative collaboration. New York: Oxford University Press.

Kapur, J.N. (1990). Some Thoughts on Creativity in Mathematics Education. In J.N. Kapur (Ed.), Fascinating world of Mathematical Sciences (pp. 131-138). New Delhi: Mathematical Sciences Trust Society.

Krutetskii, V.A. (1976). The Psychology of mathematical abilities in school children (J. Kilpatrick and I. Wizrup, eds.; J. Teller, trans.). Chicago: University of Chicago Press.

Liebert, R.M., \& Morris, L.W. (1967). Cognitive and emotional components of test anxiety: A 
distinction and some initial data. Psychological Reports, 20, 975-978.

$\mathrm{Ma}$, X. (1999). A meta-analysis of the relationship between anxiety toward mathematics and achievement in mathematics. Journal for Research in Mathematics Education, 30(5), 520-540.

Ma, X., \& Xu, J. (2004). The casual ordering of mathematics anxiety and mathematics achievement: a longitudinal panel analysis. Journal of Adolescence, 27(2), 165-179.

Mann, E.L. (2006). Creativity: The essence of mathematics. Journal for the Education of the Gifted, 30(2), 236-260.

Mann, E.L. (2009). The search for mathematical creativity: Identifying creative potential in middle school students. Creativity Research Journal, 21(4), 338-348.

Meyer, R.W. (1969). The Identification and encouragement of mathematical creativity in the first grade students. Unpublished Doctoral Dissertation, University of Wisconsin (DAI, 3 IB, 1970).

Miyan, M. (1982). Study to Examine Effectiveness of Methods of Teaching Mathematics in Developing Mathematical Creativity, Unpublished Doctoral Dissertation, Jamia Millia Islamia University, New Delhi.

Moghe, P. (1996). Developing Instructional Strategy for enhancing Creativity and Achievement in Mathematics for elementary school level, Unpublished Doctoral Dissertation, Devi Ahilya Viswavidyalyaya, Indore.

Morris, L.W., Davis, M.A., \& Hutchings, C.H. (1981). Cognitive and emotional components of anxiety: Literature review and a revised worry-emotionality scale. Journal of Educational Psychology, 73, 541-555.

NCF (2005). National Curriculum Framework. New Delhi: National Council of Educational Research and Training.

NCTM. (1989). Curriculum and evaluation standards for school mathematics. Reston, VA: Author.

NCTM. (2000). Principles and standards for school mathematics. Reston,VA, Author.

Neumann, C. J. (2007). Fostering creativity: A model for developing a culture of collective creativity in science. EMBO Reports, 8(3), 202-206. Retrieved from http://www.nature.com/embor/journal/v8 /n3/pdf/7400913.pdf

Olatunde,Y.P. (2009). Mathematics anxiety and academic achievement in some selected senior secondary schools in southwestern Nigeria. Pakistan Journal of Social Sciences, 6(3), 133-137.
Richardson, F.C., \& Suinn, R.M. (1972). The mathematics anxiety rating scale: psychometric data. Journal of Counseling Psychology, 19, 551-554.

Sarason, I.G. (1986). Test anxiety, worry and cognitive interference. In R. Schwarzer (Ed.), self-related cognitions in anxiety and motivation. Hillsdale, NJ: Erlbaum.

Sharma, Y., \& Sansanwal, D.N. (2011). Construction of a standardized scale for measuring mathematics anxiety in school children. Experiments in Education, XXXIX(1), 31-32.

Sharma, Y., \& Sansanwal, D.N. (2012, in press). Development and standardization of mathematical creativity test. The Mathematics Education, XLVI(4).

Shriki, A. (2010). Working like real mathematicians: developing prospective teachers' awareness of mathematical creativity through generating new concepts. Educational Studies in Mathematics, 73, 159-179. doi: 10.1007/s10649-009-9212-2.

Silver, E.A. (1994). On mathematical problem posing. For the Learning of Mathematics, 14(1), 19-28.

Silver, E.A. (1997). Fostering creativity through instruction rich in mathematical problem solving and problem posing. International Reviews on Mathematical Educations, 29(3), 75-80. Retrieved from http://www.emis.de/journals/ZDM/zdm97 3a3.pdf

Silver, E. A., Mamona-Downs, J., Leung, S. S. \& Kenny, P. A. (1996). Posing mathematical problems: an exploratory study. Journal for Research in Mathematics Education, 27(3), 293-309.

Singh, B. (1985). A Study of the effect of a specially designed teaching strategy and some socio-psychological factors on creativity among middle school children, Unpublished Doctoral Dissertation, Avadh University, Faizabad.

Singh, B. (2004). Teaching-learning strategies and mathematical creativity: An analysis. Indian Educational Review, 40(1), 3-21.

Sriraman, B. (2004). The characteristics of mathematical creativity. The Mathematics Educator, 14(1), 19-34.

Sriraman, B. (2005). Are giftedness \& creativity synonyms in mathematics? An analysis of constructs within the professional and school realms. The Journal of Secondary Gifted Education, 17, 20-36.

Strom, R.D., \& Strom, P.S. (2002). Changing the rules: Education for creative thinking. Journal of Creative Behavior, 36(3), 183200. 
Tocci, C.M., \& Engelhard, G., Jr. (1991). Achievement, parental support, and gender differences in attitude toward mathematics. Journal of Educational Research, 84(5), 280286.

Wigfield, A., \& Meece, J.L. (1988). Math anxiety in elementary and secondary school students. Journal of Educational Psychology, 80(2), 210-216.

Zakaria, E., \& Nordin,N.M. (2008), The Effects of mathematics anxiety on matriculation students as related to motivation and achievement. Eurasia Journal of
Mathematics, Science \& Technology Education, 4(1), 27-30.

$\diamond \diamond \diamond$

Citation Suggestions :

APA : Sharma, Y. (2014). The effects of strategy and mathematics anxiety on mathematical creativity of school students. Mathematics Education, 9(1), 25-37.

\section{APPENDIX}

\section{A. Sample of items of $\mathbf{S}^{2} \mathbf{M C T}$}

1. Using numbers $1,2,3,4,25$ and 36 and any mathematical operation get a total 9. In each answer, use each number only once. Time: 6 minutes

2. Make as many equations as you can so that '2' is at least one of the solutions. Time: 6 minutes

3. Write all the questions that you can think with first four natural numbers, that is $1,2,3$, and 4 . Time: 6 minutes

4. Observe the following given numbers. List all the common characteristics of the given numbers. Write one new number, which has all the common characteristics of the given numbers.
3902
51062
7250
Time: 3 minutes

5. Following arrangement is a way to make four identical compartments by using 9 sticks.

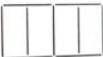

Now, try to make four identical compartments with the help of 8 sticks. Time: 5 minutes

\section{B. Sample of lessons based on strategy for fostering mathematical creativity}

\section{Lesson I}

\section{WARM-UP}

Posing Divergent Mathematical Problem and finding solutions with the help of students

If the answer is 30 , what might be the questions?

COOPERATIVE CONFRONTATION

Posing a New Divergent Problem

If the answer is 45, what might be the questions?

Students Solve the Posed Problem in a Group 
Investigator made groups of the students. Each group consisted of 4-5 students. Groups were motivated to give maximum and different responses of the problem posed by the investigator in this phase. Some of the responses given by the students were:

1. $18 \times 5 \div 2 \times 1=$ ?

2. solve $(\mathrm{x}-3)(\mathrm{x}+5)(\mathrm{x}-45)=0$

3. solve $x^{2}-2025=0$

4. solve $\mathrm{x}-45=0$

5. If cost price is Rs. 100 and selling price is Rs. 55 then what is profit?

\section{INDEPENDENT THOUGHT}

\section{Students Pose Similar Problem(s)}

Some of the problems posed by the students were:

1. If the answer is 10 , what might be the questions?

2. If the answer is 25 , what might be the questions?

3. If the answer is 111 , what might be the questions?

\section{Students Solved the Posed Problem(s) Independently}

Students solved the problems they had posed independently. At the end, Investigator wrote the most original responses of the students on the Black-Board.

\section{Lesson II}

WARM-UP

Posing Divergent Mathematical Problem and finding solutions with the help of students

Deduce other equations from the equations given below:

$\mathrm{P}-\mathrm{Q}=\mathrm{X}, \quad$ and $\mathrm{Y}=\mathrm{A}+\mathrm{X}$

\section{COOPERATIVE CONFRONTATION}

\section{Posing a New Divergent Problem}

Deduce other equations from the equations given below:

$\mathrm{B}-\mathrm{C}=\mathrm{D}, \quad \mathrm{Y}=\mathrm{A}+\mathrm{E}$, and $\mathrm{Z}=\mathrm{E}+\mathrm{C}+\mathrm{D}$

\section{Students Solve the Posed Problem in a Group}

Investigator made groups of the students. Each group consisted of 4-5 students. Groups were motivated to give maximum and different responses of the problem posed by the investigator in this phase. Some of the responses given by the students were:

$$
\begin{array}{ll}
\text { 1. } & \mathrm{B}=\mathrm{C}+\mathrm{D} \\
\text { 2. } & -\mathrm{C}=\mathrm{D}-\mathrm{B} \\
\text { 3. } & \mathrm{Z}=\mathrm{Y}-\mathrm{A}+\mathrm{C}+\mathrm{B}-\mathrm{C} \\
\text { 4. } & \mathrm{Z}=\mathrm{Y}-\mathrm{A}+\mathrm{B}
\end{array}
$$

\section{INDEPENDENT THOUGHT}

\section{Students Pose Similar Problem(s)}

Some of the problems posed by the students were:

1. Deduce other equations from the equations given below:

$$
\mathrm{X}+\mathrm{Y}+\mathrm{Z}=\mathrm{A} \text {, and } \mathrm{Y}=\mathrm{B}+\mathrm{C}
$$

2. Deduce other equations from the equations given below:

$$
\mathrm{A}+\mathrm{B}-\mathrm{C}=\mathrm{Y} \text {, and } \mathrm{C}=\mathrm{P}+\mathrm{X}
$$

3. Deduce other equations from the equations given below:

$$
\mathrm{P}+\mathrm{Q}=\mathrm{D}, \quad \mathrm{W}=\mathrm{Q}-\mathrm{F} \text {, and } \mathrm{Z}=\mathrm{F}+\mathrm{C}+\mathrm{D}
$$

4. Deduce other equations from the equations given below:

$$
\mathrm{A}-\mathrm{C}=\mathrm{D}, \quad \mathrm{Z}=\mathrm{P}+\mathrm{E} \text {, and } \mathrm{P}=\mathrm{E}+\mathrm{C}+\mathrm{D}
$$

\section{Students Solved the Posed Problem(s) Independently}

Students solved the problems they had posed independently. At the end, Investigator wrote the most original responses of the students on the Black-Board.

\section{Lesson III}

\section{Phase I: WARM-UP}

Posing Divergent Mathematical Problem and finding solutions with the help of students

The mean of number of observation(s) is 30 . What could be the observations? 


\section{Phase II: COOPERATIVE INTERACTION}

\section{Posing a New Divergent Problem}

The mean of number of observation(s) is 120 . What could be the observations?

Students Solve the Posed Problem in a Group

Investigator made groups of the students. Each group consisted of 4-5 students. Groups were motivated to give maximum and different responses of the problem posed by the investigator in this phase. Some of the responses given by the students were:

1. $(120+120) / 2$

2. $(200+200+100+50+50) / 5$

3. $(500+4000.5+20+30+50+\{-4000\}+15+45+60+479.5) / 10$

\section{INDEPENDENT THOUGHT}

\section{Students Pose Similar Problem(s)}

Some of the problems posed by the students were:

1. The mean of number of observation(s) is 75 . What could be the observations?

2. The mean of number of observation(s) is 220 . What could be the observations?

3. The mean of number of observation(s) is 620 . What could be the observations?

\section{Students Solved the Posed Problem(s) Independently}

Students solved the problems they had posed independently. At the end, Investigator wrote the most original responses of the students on the Black-Board. 